\title{
Psychological impact and sleep quality in the COVID-19 pandemic in Brazil, Colombia and Portugal
}

\section{Impacto psicológico y calidad del sueño en la pandemia de COVID- 19 en Brasil, Colombia y Portugal}

\author{
Ubaldo Enrique Rodríguez-De Avila (iD)1, Fabíola Rodrigues-De França (iD)2, Maria de Fátima Jesus-Simões (iD)3 \\ 1. Universidad del Magdalena. Santa Marta, Colombia. Correo: rodriguez.ubaldo@gmail.com - https://orcid.org/0000-0001-5907-001X \\ 2. Centro Universitário Facex - UNIFACEX. Natal, Brasil. Correo: fabiolafcampos@gmail.com - https://orcid.org/0000-0002-3850-2984 \\ 3. Universidade da Beira Interior e Centro de Investigação em Educação e Psicologia - Universidade de Évora. Portugal. Correo: simoesfati@gmail.com - \\ https://orcid.org/0000-0001-5847-8427
}

Typology: Article of scientific and technological research

To cite this article: Rodríguez-De Avila EU, Rodrigues-De França F, Simões MFJ. Psychological Impact and Sleep Quality in the COVID-19 Pandemic in Brazil, Colombia and Portugal I. Duazary. 2021 abril; 18(2): 120-130. Doi: https://doi.org/10.21676/2389783X.4074

Received on September 25 of 2020

Accepted on March 16 of 2021

Published online May 25 of 2021

\begin{abstract}
Keywords: Psychological Impact; Sleep Quality; Pandemia; COVID-19.

The study's objective is to evaluate, through an online questionnaire, the anxiety levels, suicidal thoughts, and sleep quality during the COVID-19 pandemic period with 988 participants from Colombia, Brazil, and Portugal. In these countries, $2.1 \%$ of the subjects presented with mild anxiety, $85.5 \%$ had moderate anxiety, $12 \%$ ranged from moderate to severe, and $0.3 \%$ had an extremely severe anxiety level. Suicidal thoughts were found in $57 \%$ of the participants: $31.1 \%$ moderate, $9.7 \%$ serious to severe, and $2.2 \%$ extremely severe. Regarding sleep, $14 \%$ had good sleep quality, $53.5 \%$ poor sleep quality, and $32.5 \%$ possible sleep disorders. The difference between anxiety and suicidal ideation values between countries was not significant, but there is a significant difference between the distribution of sleep quality values among countries. The differences are appreciated mainly between adolescents $1<22$ years) and people of other ages. Colombia differs from Brazil and Portugal in terms of sleep quality. In addition to the health problems brought by the COVID-19 pandemic, this study showed that the adolescent population in countries of the South American continent is more vulnerable to psychological and sleep quality impacts.
\end{abstract}

\section{RESUMEN}

El objetivo del estudio fue evaluar, a través de un cuestionario en línea, aspectos relacionados con los niveles de ansiedad, pensamientos suicidas y calidad del sueño durante el período pandémico del covid19 en tres países con 988 participantes de Colombia, Brasil y Portugal. El 2,1\% de los sujetos presentó ansiedad leve, el $85,5 \%$ niveles moderados, el $12 \%$ osciló entre moderado y severo y el 0,3\% presentó un nivel de ansiedad extremo. El pensamiento suicida se encontró al nivel del $57 \% ; 31,1 \%$ moderada, $9,7 \%$ marcada severa y $2,2 \%$ extrema. En cuanto al sueño, el $14 \%$ tenía buena calidad de sueño, el $53,5 \%$ mala calidad y el $32,5 \%$ posibles trastornos del sueño. La diferencia entre los valores de ansiedad e ideación suicida entre países no fue significativa. Sin embargo, existe una diferencia significativa entre la distribución de los valores de calidad del sueño entre países. Las diferencias se dan principalmente entre adolescentes ( $<22$ años) y otras edades. Colombia se diferencia de Brasil y Portugal en términos de calidad del sueño. Además de los problemas de salud que trajo la pandemia del covid-19, este estudio mostró que la población adolescente es más vulnerable a los impactos psicológicos y en la calidad del sueño en países del continente sudamericano. 


\section{INTRODUCCIÓN}

On March 11, 2020, COVID-19 (a disease caused by the new SARS-CoV-2 coronavirus) was raised to the highest level of alert by the World Health Organization (WHO), being recognized as a public health emergency of international importance and declared a pandemic. The confrontation with COVID-19 has placed our society in an atypical context to our ordinary routines. Each person, each family, each country has dealt with the pandemic differently. Outbreaks of COVID-19 in several countries and regions of the world led its leaders to take protective measures, including social isolation (physical distance) in the control of community transmission. Because it is an emerging disease, many studies are still being carried out, and new guidelines and recommendations from the $\mathrm{WHO}^{1}$ appear daily.

COVID-19 is already present in all continents, and the countries have adopted measures of physical isolation and stoppage of non-essential activities that already exceed 30 days. The number of deaths has passed 200 thousand worldwide. The three countries (Brazil, Colombia, and Portugal) included in the present study had $114,715,8,613$, and 26,182 thousand confirmed cases as of May 7, 2020, respectively ${ }^{2}$. To date, there is no vaccine or specific medication to prevent or treat Covid-19, and the social policies adopted are inherent to each culture and development level. How the population faces the current scenario and the psychological impacts that this pandemic can cause are still uncertain ${ }^{3}$. However, the WHO Department of Mental Health and Substance Use and even other researchers ${ }^{4}$ recognize that this moment of crisis is creating stress in the entire population and have prepared a document with messages that can be used in mental support and psychosocial well-being communications to different target groups during the outbreak ${ }^{5}$.

Negative feelings and emotions such as fear, sadness, anger, changes in routine, excessive news about the pandemic, and the economic, social, and political consequences are factors that can cause emotional discomfort leading to stress and anxiety ${ }^{6}$.
Anxiety is experienced by each individual in a particular way and is related to their experiences. For Peregrino ${ }^{7}$, the differentiation between anxiety and fear is not as evident as it may seem. For Andrade and Gorenstein ${ }^{8}$, the state of anxiety is conceptualized as a transient emotional state or condition of the human organism characterized by unpleasant feelings of tension and apprehension, consciously perceived, and by an increase in the activity of the autonomic nervous system. These feelings, in turn, can interfere with an individual's sleep quality.

Researchers have already shown that people with sleep disorders have excessive daytime sleepiness and changes in cognitive performance ${ }^{9,10}$, while good sleep quality improves immunity to viral infection ${ }^{11}$. Studies of circadian rhythms have already revealed that poor sleep habits, eating patterns, physical activity, and diet can desynchronize our biological clock and contribute to metabolic problems such as obesity and diabetes $^{12,13}$, as well as mood changes ${ }^{14}$. Even more worrying data were found in the studies by Castro and collaborators ${ }^{15}$; individuals with ARMS (mental states of risk for developing psychoses and bipolar disorder) exhibit changes in the activity-rest rhythm and probably in the patterns of the sleep-wake cycle when compared to healthy individuals. This circadian dysfunction can also appear early in the pathogenesis of some neurological diseases such as Alzheimer's ${ }^{16}$.

Another worrying psychological impact is suicidal thoughts. Researchers warn of actions to mitigate possible unintended consequences for suicide prevention and point out that economic crises are generally associated with higher suicide rates than periods of relative prosperity ${ }^{17,18}$. The empirical evidence found daily suggests that several problems can lead to suicide and, to combat it in times of pandemic, it must be identified in the ideation phase $^{19}$.

Studies have shown that large outbreaks of new or severe infectious diseases are associated with levels of anxiety that can be much higher than the risk of infection or mortality from infection ${ }^{20}$. In addition to the health problems associated with the COVID-19 
pandemic, it brings symptoms of anxiety ${ }^{21,22}$, anxiety and depression ${ }^{23,24}$, and a significant psychological or mental impact ${ }^{25,26}$.

On the other hand, it is now known that psychological well-being and sleep quality are affected by several factors, including financial burden, family support, social support, and social capital $^{27}$. Recent studies have investigated the influence of social factors on mental health ${ }^{28}$, but there is little research on the relationship between social capital and health ${ }^{29}$.

To assess the psychological impact and sleep quality during the COVID-19 pandemic period, the present study involved individuals from three countries in completing an online questionnaire that addressed anxiety levels, suicidal thoughts, and sleep quality. Another critical, exploratory hypothesis is the significant difference between suicidal ideation, anxiety, and sleep quality between men and women and in various age groups.

\section{MATERIALS AND METHODS}

\section{Kind of investigation}

Snowball sampling was used. The study was quantitative and exploratory. The instruments were created in Google Forms and sent via e-mail, WhatsApp, and Facebook. The study ran from $4 / 17 / 2020$ to $6 / 6 / 2020$ (1:49 pm) during a period of physical isolation for countries in the COVID-19 pandemic.

\section{Participants}

Nine hundred ninety-eight people aged between 18 and $\mathbf{7 4}$ years participated in this study. Participants under the age of 18 and those not residing in Brazil, Colombia, or Portugal were excluded. We established four groups by age (Table 1), $22.5 \%$ men and $77.5 \%$ women. The sample was distributed by country: Brazil (26.9\%), Portugal (26\%), and Colombia (47.1\%) (Table 1).

\section{Instruments}

Portuguese versions were administered to Brazil and Portugal and a Spanish version to Colombia. We verified the semantic adjustment of the different versions. The validity criteria of the instruments are reported below.

Zung Self-Rating Anxiety Scale-15 (SAS-15): SAS is a measure designed by Zung in 1971 that quantifies the levels of anxiety-related symptoms ${ }^{30}$. It is a selfadministered questionnaire that originally had 20 items; each item is rated on a scale of 1 to 4 (none of the time, some of the time, good part of the time, and most of the time). Since its inception, the scale has been used by the scientific community and is currently employed in studies of the COVID-19 pandemic situation ${ }^{21,22}$. This questionnaire was previously validated in both languages ${ }^{31,32}$. In the present study, the average of the total score is obtained for the SAS-15 intervals $1<1=$ normal; $1.01-2=$ mild to moderate; $2.01-3=$ serious to severe; $3.01-4$ = extremely severe).

Exploratory Factor Analysis (EFA) reduced the Scale to 15 factors, with an appropriate psychometric adjustment in both versions (Portuguese and Spanish). Cronbach's alpha ( $\alpha$ ) in general was $\alpha=$ 0.849 with $K M O=0.904$, Bartlett's test of sphericity was $X^{2}(105)=3901.807 ; p<0.01$, and the total variance explained with a single identified factor was $33.4 \%$. This information confirms a good psychometric adjustment of the SAS-15.

The psychometric behavior of the questionnaires by language was as follows: Portuguese $(N=523): \alpha=$ $0.845 ; K M O=0.885 ;$ Bartlett's sphericity: $X^{2}(105)=$ $2340.913, p<0.01$; total explained variance $=$ $33.92 \%$. Spanish $(N=465): \alpha=0.858 ; K M O=0.901$; Bartlett's sphericity: $X^{2}(105)=1922.645, p<0.01$; total explained variance $=34.64 \%$.

Okasha's Suicidality Scale (OSS) (1981): It consists of four items rated on a Likert scale from 1 to 4 (never, sometimes, usually, and always). In the present study, the average of the total score to obtain suicidality intervals is defined in the parentheses $(<1=$ normal; $1.01-2=$ mild to moderate; $2.01-3=$ serious to severe; $3.01-4=$ extremely severe). This study is believed to be the 
first formal one to report statistical validity for the Portuguese language. For Colombian Spanish, there are already previous validation reports ${ }^{32}$. The general EFA is as follows: $\alpha=0.85 ; K M O=0.769$; Bartlett's sphericity: $X^{2}(6)=2159.354, p<0.01$; total explained variance $=71.51 \%$. A good psychometric adjustment is verified.

The psychometric behavior of the instruments by language was as follows: Portuguese $(N=523): \alpha=$ $0.845 ; K M O=0.742 ;$ Bartlett's sphericity: $X^{2}(6)=$ $1160.947, p<0.01$; total explained variance $=$ $70.63 \%$. Spanish $(N=465): \alpha=0.865 ; K M O=0.787$; Bartlett's sphericity: $X^{2}(6)=1018.349 ; p<0.01$; total explained variance $=72.58 \%$.

Pittsburgh Sleep Quality Index (PSQI): The PSQI is a questionnaire widely used in the scientific community, validated in several languages. It contains a total of 19 questions, grouped into ten themes/areas. The 19 questions come together to form seven areas (subjective sleep quality, sleep latency, sleep duration, sleep efficiency, sleep disturbance, sleep medication, dysfunction during the day) with their relevant score, each showing an interval between 0 and 3 points. In all cases, a score of " 0 " indicates ease, while a score of " 3 " indicates serious difficulty within the respective area. The score for the seven areas is finally added to obtain a total PSQI score, which ranges from 0 to 21 points, with " 0 " indicating ease of sleep and " 21 " severe difficulty in all areas. These values were didactically grouped into three ranges: good sleep quality, poor sleep quality, and sleep disorder ${ }^{33}$. In the present research, the EFA verified a psychometric adjustment: $\alpha=0.647$ and $K M O=0.803$. Bartlett's test of sphericity was also adequate $\left(X^{2}(136)=\right.$ $3769.667 ; p<0.01)$, and the total explained variance was between 23.73 and $50.82 \%$.

The psychometric behavior of the instruments by language was as follows: Portuguese $(N=523): \alpha=$ $0.707 ; K M O=0.848$; Bartlett's sphericity: $X^{2}(136)=$ 2507.543; $p<0.01$; total explained variance $=29.07$ to $58.29 \%$. For the instrument in Spanish, EFA could not be performed because at least one of the variables has zero variation, and the correlation coefficient between the elements could not be calculated; however, this did not affect the overall integrated reliability of the two languages. Further study with Confirmatory Factor Analysis (CFA), in addition to EFA, is recommended.

\section{Data analysis}

For all variables, the median (ME), mean (M), and standard deviation $( \pm)$ were estimated. The Kolmogorov-Smirnov test was performed to discover their distribution. We verified the nonnormal distribution in all variables. For this reason, Spearman's correlation estimate was applied. We verified the intergroup variance in all variables using the Kruskal-Wallis test, and the post hoc was estimated with Kruskal-Wallis adjusted probability ( $p$-adjust). Statistical analyses were performed using the statistical program Statistical Package for the Social Sciences (SPSS), version 22.0 for Windows.

The psychometric adjustment of the instruments was determined from Cronbach's alpha $(\alpha)$, Bartlett's test sphericity, Kaiser, Meyer, and Olkin test (KMO), and the total explained variance. In all analyses, we considered a p-value of 0.05 and a $95 \%$ confidence interval.

\section{Statements on ethical aspects}

We carried out the research according to Resolution 8430 , which regulates health research, and the specific regulations of the Colombian College of Psychologists, under Law 1090 of 2006 in Colombia. It was submitted and approved by the ethics committee of the Universidad del Magdalena Faculty of Health Sciences. The free and informed consent was signed online.

\section{RESULTS}

The descriptions corresponding to each country are described graphically in Table 1 below: 
Table 1. Variables of the subjects and sociodemographic data.

\begin{tabular}{|l|c|c|c|c|c|}
\hline \multicolumn{7}{|c|}{ Sociodemographic characteristics of the study sample } \\
\hline Variables & Brazil & Portugal & Colombia & Total & $\mathbf{X}^{\mathbf{2}}$ \\
\hline $\mathrm{n}$ (Middle and Age) & $\mathrm{n}=266(37 \pm 11)$ & $\mathrm{n}=257(41 \pm 14)$ & $\mathrm{n}=465(30 \pm 11)$ & $\mathrm{n}=988(35 \pm 13)$ & \\
\hline Sex $(\mathrm{n}$ and \%) & $203(76.3 \%)$ & $219(85.2 \%)$ & $344(74 \%)$ & $766(77.5 \%)$ & $12.29(2)$ \\
\hline & $63(23.7 \%)$ & $38(14.8 \%)$ & $121(26 \%)$ & $222(22.5 \%)$ & $\mathrm{p}=0.002$ \\
\hline Femele & $29(10.9 \%)$ & $26(10.1 \%)$ & $148(31.8 \%)$ & $203(20.5 \%)$ & \\
\hline Male & $78(29.3 \%)$ & $58(22.6 \%)$ & $162(34.8 \%)$ & $298(30.2 \%)$ & $119.482(2)$ \\
\hline Age Range $(\mathrm{n}$ and \%) & $95(35.7 \%)$ & $64(24.9 \%)$ & $95(20.4 \%)$ & $254(25.7 \%)$ & $\mathrm{p}<0.001$ \\
\hline$\leq 22$ years & $64(24.1 \%)$ & $109(42.4 \%)$ & $60(12.9 \%)$ & $233(23.6 \%)$ & \\
\hline 23 - 33 years &
\end{tabular}

$\mathbf{X}^{2}=$ Kruskal-Wallis Chi Square.

Nine hundred eighty-eight subjects answered the online questionnaire, 266 residents in Brazil, 257 in Portugal, and 465 in Colombia. Most of them were female $(77.5 \%)$. Age was grouped by group where $20.5 \%$ were 22 years old or younger, 30.2 were between 23 and 33 years old, $25.7 \%$ were between 24 and 44 years old, and $23.6 \%$ were over 44 years old. There was a difference between countries in relation to sex $\left[X^{2}(2)=12.290 ; p=0.002\right]$ and age groups $\left(X^{2}(2)=119.482 ; p<0.01\right)$.

The frequency of anxiety scores showed that $2.1 \%$ of the studied subjects had mild anxiety, $85.5 \%$ had moderate anxiety levels, $12 \%$ had an anxiety level that ranged from serious to severe, and only $0.3 \%$ (three subjects) had extremely severe anxiety. Concerning suicidal ideation, $57 \%$ of the participants had a slight level of suicidal thoughts, $31.1 \%$ had a moderate level, $9.7 \%$ had serious or severe suicidal thoughts, and $2.2 \%$ had an extremely severe level. As for sleep quality, $14 \%$ had good sleep quality, $53.5 \%$ poor sleep quality, and $32.5 \%$ possible sleep disorders.

Correlations showed inverse associations between age and all variables, which means that anxiety and suicidal ideation values are higher in the younger age groups, and the younger the subjects, the worse the sleep quality (Table 3 ). Positive correlations were also found between anxiety and suicidal thoughts, anxiety and sleep quality, and suicidal ideation and sleep quality, which means that poor sleep quality is associated with high levels of anxiety and suicidal thoughts (Table 3 ).
Table 2. Descriptors and normality test.

\begin{tabular}{|c|c|c|c|c|c|c|}
\hline Variables & Min & Max & Me & M & \pm & KS \\
\hline Age & 18 & 74 & $\begin{array}{r}33 . \\
00\end{array}$ & $\begin{array}{r}35.0 \\
7\end{array}$ & 13.01 & $\begin{array}{r}0.096(987) \\
*\end{array}$ \\
\hline SAS-15 & 1.00 & 3.20 & $\begin{array}{r}1.4 \\
6\end{array}$ & $\begin{array}{r}1.52 \\
3\end{array}$ & 0.39 & $\begin{array}{r}0.395(987) \\
*\end{array}$ \\
\hline IS & 1.00 & 3.75 & $\begin{array}{r}1.0 \\
0 \\
\end{array}$ & $\begin{array}{r}1.37 \\
5 \\
\end{array}$ & 0.59 & $\begin{array}{r}0.591(987) \\
*\end{array}$ \\
\hline PSQI & 1.00 & $\begin{array}{r}20.0 \\
0\end{array}$ & $\begin{array}{r}8.0 \\
0\end{array}$ & $\begin{array}{r}7.90 \\
7\end{array}$ & 3.58 & $\begin{array}{r}1.710(987) \\
*\end{array}$ \\
\hline
\end{tabular}

$\mathbf{N}=988$. Min= Minimum. Max $=$ Maximum. $\mathbf{M e}=$ Median. $\mathbf{M}=$ Mean $\pm=$ Standard deviation.

KS= Kolmogorov-Smirnov test, with correction of the significance of Lilliefors.

$*=p<0,01=$ Non-Normal Distribution.

Table 3. Correlation statistics.

\begin{tabular}{|l|l|l|l|l|}
\hline & Age & SAS-15 & IS & SPQI \\
\hline Age & ----- & & & \\
\hline SAS-15 & $-0.253^{*}$ & ------- & & \\
\hline IS & $-0.244^{*}$ & $0.349 *$ & ------- & \\
\hline PSQI & $-0.199 *$ & $0.554^{*}$ & $0.294^{*}$ & ------ \\
\hline
\end{tabular}

$* \mathrm{P}<0,01$ Spearman's correlation coefficient (Rho).

Table 4 describes the variables Anxiety (SAS-15), Suicidal Ideation (OSS), and Sleep Quality (SPQI) by age groups to compare the behavior in the distribution of their values. 
Table 4. Description segmented by age.

\begin{tabular}{|c|c|c|c|c|c|}
\hline \multirow[b]{2}{*}{ Variable } & \multicolumn{4}{|l|}{ Age $(N=988)$} & \multirow[t]{2}{*}{$x^{2}$} \\
\hline & $\begin{array}{l}\leq 22 \text { years } \\
(n=203)\end{array}$ & $\begin{array}{l}23-33 \text { years } \\
(n=298)\end{array}$ & $\begin{array}{l}34-44 \text { years } \\
(n=254)\end{array}$ & $\begin{array}{l}>44 \text { years } \\
(n=233)\end{array}$ & \\
\hline SAS-15 (M, \pm$)$ & $1.73 \pm 0.44$ & $1.58 \pm 0.36$ & $1.47 \pm 0.35)$ & $1.49 \pm 0.37$ & $20.22(2) ; p<0.01$ \\
\hline Mild (\%) & 0.5 & 3.0 & 1.6 & 3.0 & \\
\hline Moderate (\%) & 77.3 & 84.6 & 91.3 & 87.6 & \\
\hline Marked to severe (\%) & 21.2 & 12.4 & 7.1 & 9.0 & \\
\hline Extreme (\%) & 1.0 & 0 & 0 & 0.4 & \\
\hline IS (M, \pm ) & $1.67 \pm 0.77$ & $1.41 \pm 0.58$ & $1.23 \pm 0.44$ & $1.22 \pm 0.44$ & $22.867(2) ; p<0.01$ \\
\hline Mild (\%) & 39.4 & 52.0 & 66.9 & 67.8 & \\
\hline Moderate (\%) & 35.0 & 34.9 & 28.0 & 26.2 & \\
\hline Marked to severe (\%) & 17.7 & 11.7 & 4.3 & 6.0 & \\
\hline Extreme (\%) & 7.9 & 1.3 & 0.8 & 0 & \\
\hline PSQI-Total $(M, \pm)$ & $9.17 \pm 3.02$ & $8.28 \pm 3.30$ & $7.75 \pm 3.57$ & $7.51 \pm 4.12$ & $9.310(2) ; p=0.01$ \\
\hline Good Sleep quality & 4.9 & 10.4 & 17.3 & 22.7 & \\
\hline Sleep quality Poor & 52.7 & 57.0 & 55.5 & 47.6 & \\
\hline Sleep disturbance & 42.04 & 32.6 & 27.2 & 29.6 & \\
\hline
\end{tabular}

$\mathbf{M}=$ Mean. $\mathbf{\pm}=$ Standard deviation. $\mathbf{X}^{\mathbf{2}}=$ Kruskal-Wallis Chi Square

The older subjects in the sample (> 34 years old) do not differ in terms of suicidal ideation (most have mild levels). The younger the subjects in the sample, the higher the levels of suicidal thoughts. The Kruskal-Wallis post hoc with adjusted significance determined the same statistical behavior between the values of SAS-15 and OSS, which means that anxiety behaves in the same way as suicidal ideation (Figure 1).

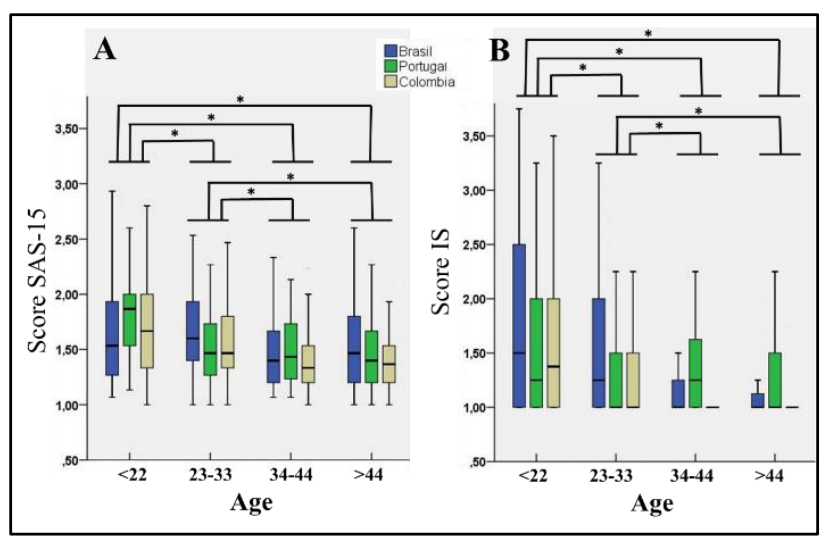

Figure 1. Box plot of SAS-15 and IS values, by age. A. SAS-15 values. B. IS values. $*=p<0.01$ (post hoc Kruskal-Wallis).
Table 5 describes the variables Anxiety (SAS-15), Suicidal Thoughts (OSS), and Sleep Quality (PSQI) by countries to compare the behavior in the distribution of their values.

The Kruskal-Wallis post hoc with adjusted significance ( $p$-adjust) determined no significant difference between anxiety and suicidal ideation values among countries. However, countries differ in terms of sleep quality: Colombia differs from Brazil and Portugal (Figure 2C). The differences found are mainly between adolescence $(\leq 22$ years) and the other ages for SPQI (Figure 2A). The correlation graph between these two variables shows that the SPQI scores decrease with advanced age. This behavior was common in the three countries (Figure 2B). 
Table 5. Description segmented by Countries.

\begin{tabular}{|c|c|c|c|c|}
\hline \multirow[b]{2}{*}{ Variables } & \multicolumn{3}{|c|}{ Countries $(\mathrm{N}=988)$} & \multirow[b]{2}{*}{$x^{2}$} \\
\hline & $\begin{array}{l}\text { Brazil } \\
(n=266)\end{array}$ & Portugal $(n=257)$ & $\begin{array}{l}\text { Colombia } \\
(n=465)\end{array}$ & \\
\hline SAS-15 (M, \pm$)$ & $1.58 \pm 0,42$ & $1.53 \pm 0.36$ & $1.56 \pm 0.39$ & $15.455(2) p<0.01$ \\
\hline Mild (\%) & 1.21 & 2.3 & 2.6 & \\
\hline Moderate (\%) & 83.8 & 89.1 & 84.5 & \\
\hline Marked to severe (\%) & 14.3 & 8.6 & 12.7 & \\
\hline Extreme (\%) & 0.8 & 0 & 0.2 & \\
\hline IS (M, \pm ) & $1.38 \pm 0.59$ & $1.37 \pm 0.55$ & $1.37 \pm 0.60$ & $30.168(2) p<0.01$ \\
\hline Mild (\%) & 56.8 & 52.1 & 59.8 & \\
\hline Moderate (\%) & 32.3 & 35.8 & 27.7 & \\
\hline Marked to severe (\%) & 7.9 & 11.3 & 9.9 & \\
\hline Extreme (\%) & 3.0 & 0.8 & 2.6 & \\
\hline PSQI-Total (M, \pm ) & $7.33 \pm 3.73$ & $7.39 \pm 4.24$ & $9.04 \pm 2.79$ & $9.009(2) p=0.01$ \\
\hline Sleep quality Good & 22.2 & 27.2 & 1.9 & \\
\hline Sleep quality Poor & 53.8 & 44.0 & 58.7 & \\
\hline Sleep disturbance & 24.1 & 28.8 & 39.4 & \\
\hline
\end{tabular}

$\mathbf{M}=$ Mean. $\mathbf{\pm}=$ Standard deviation. $\mathbf{X 2}=$ Kruskal-Wallis Chi Square.

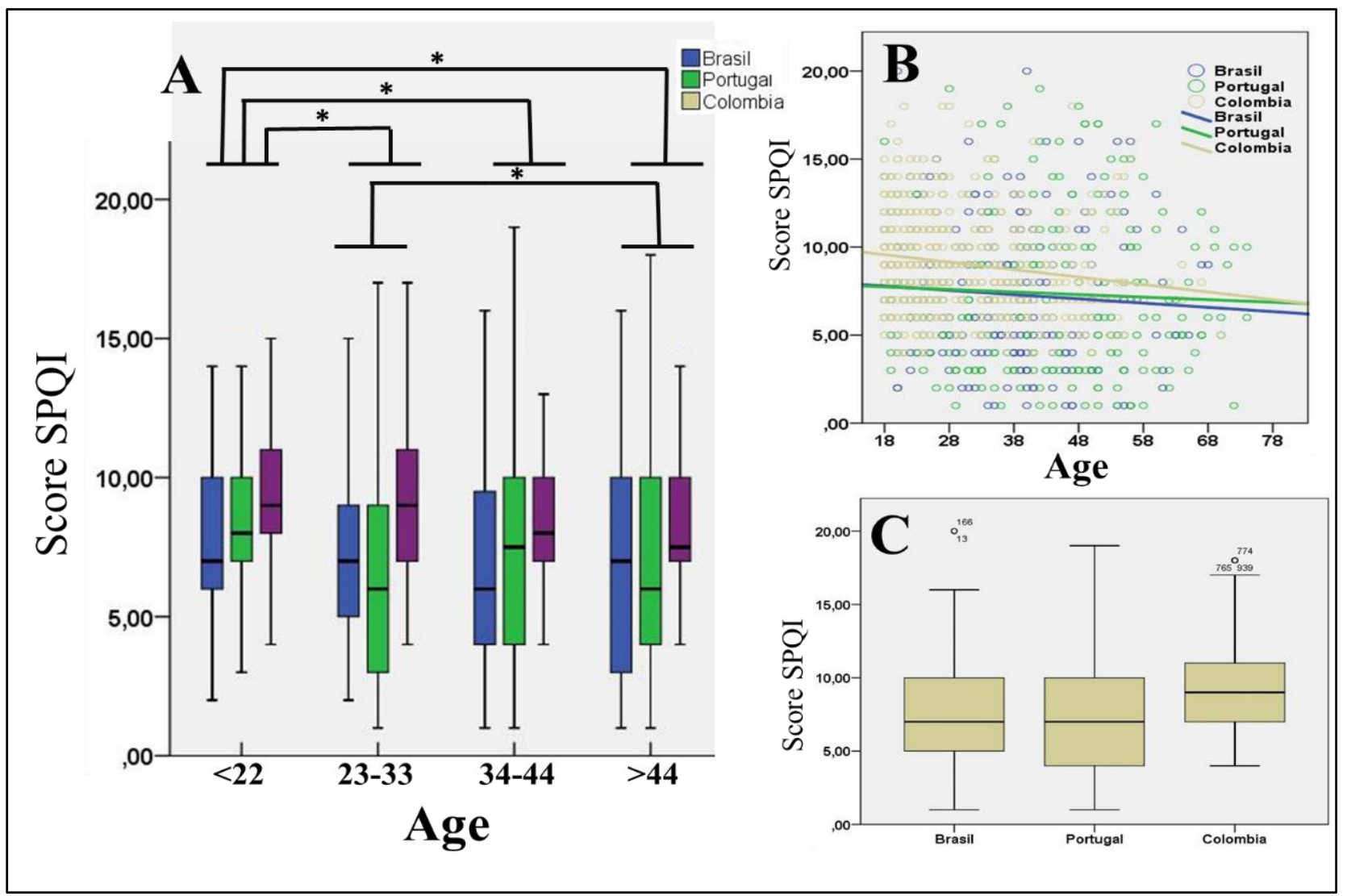

Figure 2. Distribution of SPQI values. A. SPQI Box plot regarding Age. B. Dispersion of SPQI values with respect to Age. C. Box plot of SPQI values for countries. ${ }^{*}=p<0,01$ (Kruskal-Wallis post hoc). 


\section{DISCUSSION}

Healthy sleep comprises many dimensions, including adequate duration, good quality, and absence of sleep disorders ${ }^{10}$. Chronic insufficient sleep has become a concern due to its association with morbidity and mortality, for example, obesity, type 2 diabetes, hypertension, cardiovascular diseases, depression, among others ${ }^{34-37}$. Our interest in this study is to understand how people slept during the period of social isolation due to the COVID-19 pandemic. We know that a certain amount of stress (cognitive, physiological, environmental) disturbs the sleep system, causing individuals with high sleep reactivity (propensity to sleep problems) to experience disorders such as difficulty falling asleep and sleep interruption. This deterioration is also associated with the risk of disorders such as depression and anxiety ${ }^{38}$.

There were $85.5 \%$ moderate anxiety levels; $12 \%$ of the anxiety level ranged from serious to severe, and only $0.3 \%$ (three individuals) had an extremely severe level of anxiety. Suicidal thoughts were found in $57 \%$ of the population; $31.1 \%$ moderate, $9.7 \%$ serious or severe, and $2.2 \%$ extremely severe. As for sleep, $14 \%$ had good sleep quality, $53.5 \%$ poor sleep quality, and $32.5 \%$ possible sleep disorders. It was also found that the difference between the values of anxiety and suicidal ideation among countries was not significant. However, there is a significant difference between the distribution of sleep quality values among countries. The analysis indicated that the differences are mainly between adolescence ( $\leq 22$ years) and other ages. Colombia differed from Brazil and Portugal in terms of sleep quality. In addition to the health problems that the COVID-19 pandemic brings, the present study showed that the adolescent population was the most vulnerable to psychological impacts and sleep quality, especially in the countries of the South American continent.

The results showed that the subgroup of people aged 22 years or younger represented the group most at risk for extremely severe suicidal ideation. However, the analysis of variance did not show a significant difference for the sex groups, while a significant difference was found for the age subgroups. Post hoc confirmed a significant difference between age groups, with young people aged 22 years or younger (men and women) being the group most at risk for suicidal ideation.

Most of the participants had difficulty sleeping. The analysis of variance using the Kruskal-Wallis adjusted probability showed a significant difference between the subgroups aged 22 years or younger and over 44 years, which proved that young people find it easier to sleep than adults. The results agree with previous reports ${ }^{21,22}$.

People aged 22 years or younger remain a population group with a higher risk of suffering from profound psychopathologies, leading to suicide. It is necessary to develop emotional restraint programs and strengthen the existing ones, providing comprehensive care mechanisms that include psychological and social factors as the pandemic situation is treated medically and epidemiologically. We recommend that future research expand other study variables that include family education and other sociological aspects to determine the relationship between them.

\section{ACKNOWLEDGMENTS}

Sincere thanks to all participating institutions and volunteers.

\section{DECLARATIONS AND CONFLICTS OF INTEREST}

The researchers declare that there is no conflict of interest.

\section{BIBLIOGRAPHIC REFERENCES}

1. Enfermedad por el Coronavirus (COVID-19) I OPS/OMS | Organización Panamericana de la Salud. Available at: https://www.paho.org/es/tag/enfermedad-porcoronavirus-covid-19

2. Coronavirus disease (COVID-19) - World Health Organization [Internet]. Available at: 
https://www.who.int/emergencies/diseases/novelcoronavirus-2019

3. Guo J, Liao L, Wang B, Li X, Guo L, Tong Z, et al. Psychological Effects of COVID-19 on Hospital Staff:

A National Cross-Sectional Survey of China Mainland. Rochester, NY: Social Science Research Network; 2020.2 Doi: https://doi.org/10.2139/ssrn.3550050

4. Brooks SK, Webster RK, Smith LE, Woodland L, Wessely S, Greenberg N, et al. The psychological impact of quarantine and how to reduce it: rapid review of the evidence. The Lancet. 2020; 395(10227):912-20.

Doi: https://doi.org/10.1016/S0140-6736(20)30460-8

5. WHO Director-General's opening remarks at the media briefing on COVID-19; 2020. Available at: https://www.who.int/director-

general/speeches/detail/who-director-general-sopening-remarks-at-the-media-briefing-on-covid19---18-march-2020

6. Universidade Federal Da Paraíba - UFPB Centro de Referência em Atenção à Saúde - CRAS. Cartilha psicovida; 2020.2 Available at: https://www.ufpb.br/cras/contents/documentos/c artilha-psicovida.pdf/view

7. Peregrino A. Ansiedade normal e patologica. Jornal brasileiro de psiquiatria. 1996;45(3):129-34. Available at: https://www.worldcat.org/title/ansiedade-normale-patologica/oclc/69966911\#borrow

8. Andrade LHSG de, Gorenstein C. Aspectos gerais das escalas de avaliacao de ansiedade. Rev psiquiatr clín (São Paulo). 1998;285-90. Available at: https://pesquisa.bvsalud.org/portal/resource/pt/lil $-236702$

9. Zitting K-M, Vujovic N, Yuan RK, Isherwood CM, Medina JE, Wang W, et al. Human Resting Energy Expenditure Varies with Circadian Phase. Current Biology. 2018;28(22):3685-3690.e3. Doi: https://doi.org/10.1016/j.cub.2018.10.005

10. Chaput J-P, Dutil C, Sampasa-Kanyinga H. Sleeping hours: what is the ideal number and how does age impact this? [Internet]. Vol. 10, Nature and
Science of Sleep. Dove Press; 2018. p. 421-30. Available at: https://www.dovepress.com/sleepinghours-what-is-the-ideal-number-and-how-doesage-impact-this-peer-reviewed-article-NSS https://doi.org/10.2147/NSS.S163071

11. Gamaldo AA, Beydoun MA, Beydoun HA, Liang $H$, Salas RE, Zonderman $A B$, et al. Sleep Disturbances among Older Adults in the United States, 20022012: Nationwide Inpatient Rates, Predictors, and Outcomes. Front Aging Neurosci. 2016;8. Available at:

https://www.frontiersin.org/articles/10.3389/fnagi .2016.00266/full

https://doi.org/10.3389/fnagi.2016.00266

12. Carneiro C, Gunnarsson TG, Alves JA. Why Are Whimbrels Not Advancing Their Arrival Dates Into Iceland? Exploring Seasonal and Sex-Specific Variation in Consistency of Individual Timing During the Annual Cycle. Front Ecol Evol. 2019;7. Doi: https://doi.org/10.3389/fevo.2019.00248

13. Shan Z, Ma H, Xie M, Yan P, Guo Y, Bao W, et al. Sleep Duration and Risk of Type 2 Diabetes: A Metaanalysis of Prospective Studies. Diabetes Care. 2015;38(3):529-37. https://doi.org/10.2337/dc14-2073

14. Rock PL, Roiser JP, Riedel WJ, Blackwell AD. Cognitive impairment in depression: a systematic review and meta-analysis. Psychological Medicine. 2014;44(10):2029-40.

Doi:

https://doi.org/10.1017/S0033291713002535

15. Castro J, Zanini M, Gonçalves B da SB, Coelho FMS, Bressan R, Bittencourt $L$, et al. Circadian restactivity rhythm in individuals at risk for psychosis and bipolar disorder. Schizophrenia Research. 2015;168(1):50-5. Doi: https://doi.org/10.1016/j.schres.2015.07.024

16. Musiek ES, Bhimasani M, Zangrilli MA, Morris JC, Holtzman DM, Ju Y-ES. Circadian Rest-Activity Pattern Changes in Aging and Preclinical Alzheimer Disease. JAMA Neurol. 2018;75(5). Doi: https://doi.org/10.1001/jamaneurol.2017.4719

17. Bahamón MJ, Alarcón-Vásquez $\mathrm{Y}$, Reyes Ruiz L, Uribe Alvarado Jl, García Galindo C. Prácticas parentales como predictoras de la ideación suicida 
en adolescentes colombianos. Psicogente. 2017;21(39). Doi: https://doi.org/10.17081/psico.21.39.2821

18. Reger MA, Stanley IH, Joiner TE. Suicide Mortality and Coronavirus Disease 2019-A Perfect Storm? JAMA Psychiatry; 2020. Doi: https://doi.org/10.1001/jamapsychiatry.2020.1060

19. Rodríguez $U$, Rodrigues-deFrança Campos $F$, Chionbacanga-Nafital A, Ceballos-ospino G, PabaBarbosa C. Las inteligencias, emociones y cronotipo, ¿explican el desempeño académico en universitarios? educ.humanismo. 2019;22(38):1-21. Doi: https://doi.org/10.17081/eduhum.22.38.3636

20. Leung GM, Lam T-H, Ho L-M, Ho S-Y, Chan BHY, Wong IOL, et al. The impact of community psychological responses on outbreak control for severe acute respiratory syndrome in Hong Kong. Journal of Epidemiology \& Community Health. 2003;57(11):857-63.

Doi:

https://doi.org/10.1136/jech.57.11.857

21. Xiao H, Zhang Y, Kong D, Li S, Yang N. Social Capital and Sleep Quality in Individuals Who SelfIsolated for 14 Days During the Coronavirus Disease 2019 (COVID-19) Outbreak in January 2020 in China. Med Sci Monit. 2020;26. Doi: https://doi.org/10.12659/MSM.923921

22. Xiao H, Zhang Y, Kong D, Li S, Yang N. The Effects of Social Support on Sleep Quality of Medical Staff Treating Patients with Coronavirus Disease 2019 (COVID-19) in January and February 2020 in China. Med Sci Monit. 2020;26:e923549-1-e923549-8. Doi: https://doi.org/10.12659/MSM.923549

23. Liu D, Ren Y, Yan F, Li Y, Xu X, Yu X, et al. Psychological Impact and Predisposing Factors of the Coronavirus Disease 2019 (COVID-19) Pandemic on General Public in China. SSRN Journal; 2020. Doi: https://doi.org/10.2139/ssrn.3551415

24. Zhu J, Sun L, Zhang L, Wang H, Fan A, Yang B, et al. Prevalence and Influencing Factors of Anxiety and Depression Symptoms in the First-Line Medical Staff Fighting Against the COVID-19 in Gansu. SSRN
Journal.

2020.

Doi: https://doi.org/10.2139/ssrn.3550054

25. Liu X, Liu J, Zhong X. Psychological State of College Students During COVID-19 Epidemic. Rochester, NY: Social Science Research Network; 2020. Doi: https://doi.org/10.2139/ssrn.3552814

26. Gao J, Zheng P, Jia $Y$, Chen $\mathrm{H}$, Mao $\mathrm{Y}$, Chen $\mathrm{S}$, et al. Mental Health Problems and Social Media Exposure During COVID-19 Outbreak. Rochester, NY: Social Science Research Network. Doi: https://doi.org/10.2139/ssrn.3541120

27. Mehnert A, Lehmann C, Graefen $M$, Huland $H$, Koch U. Depression, anxiety, post-traumatic stress disorder and health-related quality of life and its association with social support in ambulatory prostate cancer patients. Eur J Cancer Care (Engl). 2010;19(6):736-45.

Doi: https://doi.org/10.1111/j.1365-2354.2009.01117.x

28. Guruge S, Thomson MS, George U, Chaze F. Social support, social conflict, and immigrant women's mental health in a Canadian context: a scoping review. Journal of Psychiatric and Mental Health Nursing. 2015;22(9):655-67. Doi: https://doi.org/10.1111/jpm.12216

29. McDonald K. Social Support and Mental Health in LGBTQ Adolescents: A review of the literature. Issues in Mental Health Nursing. 2018;39(1):16-29. Doi:

https://doi.org/10.1080/01612840.2017.1398283

30. Zung WWK. A Rating Instrument For Anxiety Disorders. Psychosomatics. 1971;12(6):371-9. Doi: https://doi.org/10.1016/S0033-3182(71)71479-0

31. Ponciano E, Serra A, Relvas J. Aferição da escala de autoavaliaçãode ansiedade de Zung, numa amostra de população portuguesa I: Resultados da aplicação numa amostra de população normal. Psiquiatria Clínica. 1982;3(4):191-202. Doi: https://doi.org/10.4236/oalib.1106100

32. Avila UER, Leon-Valle ZL, Ceballos-Ospino GA. Comportamiento psicométrico de la Zung SelfRating Anxiety Scale-15 (SAS-15) versión español, 
durante el aislamiento físico por pandemia por Covid-19. $\quad$ 2020;17(3):7-9. Doi: https://doi.org/10.21676/2389783X.3469

33. Buysse DJ, Reynolds CF, Monk TH, Berman SR, Kupfer DJ. The Pittsburgh Sleep Quality Index: a new instrument for psychiatric practice and research. Psychiatry Res. 1989;28(2):193-213. Doi: https://doi.org/10.1016/0165-1781(89)90047-4

34. Wu Y, Zhai L, Zhang D. Sleep duration and obesity among adults: a meta-analysis of prospective studies. Sleep Medicine. 2014;15(12):1456-62. Doi: https://doi.org/10.1016/j.sleep.2014.07.018

35. Wang D, Li W, Cui X, Meng Y, Zhou M, Xiao L, et al. Sleep duration and risk of coronary heart disease: A systematic review and meta-analysis of prospective cohort studies. International Journal of Cardiology. 2016;219:231-9. Doi: https://doi.org/10.1016/j.ijcard.2016.06.027

36. Zhai L, Zhang H, Zhang D. Sleep Duration and Depression Among Adults: A Meta-Analysis of Prospective Studies. Depression and Anxiety. 2015;32(9):664-70.

Doi:

https://doi.org/10.1002/da.22386

37. Shen X, Wu Y, Zhang D. Nighttime sleep duration, 24-hour sleep duration and risk of all-cause mortality among adults: a meta-analysis of prospective cohort studies. Sci Rep. 2016 Feb 22;6:21480.

Doi:

https://doi.org/10.1038/srep21480

38. Kalmbach DA, Anderson JR, Drake CL. The impact of stress on sleep: Pathogenic sleep reactivity as a vulnerability to insomnia and circadian disorders. Journal of Sleep Research. 2018;27(6):e12710. Doi: https://doi.org/10.1111/jsr.12710 